\title{
O efeito da interação social entre os jovens nas decisões de consumo de álcool, cigarros e outras drogas ilícitas
}

\author{
Kalinca Léia Becker \\ Professora - Universidade Federal de Santa Maria (UFSM) \\ Endereço: Rua Floriano Peixoto, 1750 - Centro Santa Maria - Rio Grande do Sul \\ CEP: 97015-372 - E-mail: kalincabecker@gmail.com \\ Recebido: 06/07/2015. Aceite 04/11/2016.
}

\section{Resumo}

Este estudo analisou a influência do efeito das interações sociais dos jovens nas escolas, pública e privada, sobre as decisões de consumo de drogas ilícitas, álcool ou cigarro. Para isso, foram estimadas equações de comportamento individual com instrumentos para as interações sociais e dados da Pesquisa Nacional de Saúde do Escolar de 2012. Os resultados indicaram que o efeito destas interações nas decisões de consumo de substâncias ilícitas são maiores em comparação à influência das características das famílias. Por exemplo, transferir um jovem de escola pública, onde $80 \%$ dos alunos fumam, para uma escola onde esta taxa é de $50 \%$, compensaria completamente o maior risco de o jovem fumar associado ao fato de um dos pais fumar. Além disso, os resultados apontaram que o envolvimento dos pais com as atividades dos filhos pode ser mais importante para inibir o consumo de drogas, álcool e cigarros do que a escolaridade dos pais e o nível de vida da família.

\section{Palavras-Chave}

Interação social. Decisão de consumo. Drogas.

\begin{abstract}
This study analyzed the influence of the social interactions effect of young people in schools, public and private, on the consumption decisions of illicit drugs, alcohol or cigarettes. For this, individual behavior equations were estimated with instruments for social interactions and data from the National School of Health, 2012. The results indicated that the effect of these interactions on consumption decisions of illicit substances are higher compared to the influence of characteristics families. For example, moving a young in a public school where $80 \%$ of students smoke to a school where this rate is $50 \%$ would completely offset the higher risk of youth smoking associated with the fact of a parent smoking. In addition, the results showed that parental involvement with the activities of the children may be more important to inhibit the consumption of drugs, alcohol and cigarettes than parents' education and family living standards.
\end{abstract}

\section{Keywords}

Social interaction. Consumption decision. Drugs.

\author{
JEL Classification \\ D70. D12. 112.
}




\section{Introdução}

O consumo de drogas entre os jovens é um fenômeno de grande preocupação social, pois, além de gerar um mercado consumidor para uma atividade ilícita, ocasionando problemas jurídicos, sociais e de violência, pode comprometer de forma permanente a capacidade cognitiva destes jovens, desencadear distúrbios neurológicos e outros problemas de saúde. ${ }^{l}$ Esta situação também causa problemas econômicos, pois aumenta a demanda pelo sistema público de saúde, gerando maiores gastos, e pode prejudicar a formação da força de trabalho, tanto pelo comprometimento cognitivo dos usuários como também pelas possíveis vítimas da violência ocasionada pelo tráfico de drogas e pelas mortes no trânsito devido ao uso do álcool.

As informações do Sistema Único de Saúde (DATASUS) revelam que foram gastos, em média, cerca de $\mathrm{R} \$ 60$ milhões em 2012 com pessoas dependentes do álcool, e que $21,8 \%$ dos jovens com idade entre 18 e 24 realizaram consumo abusivo de bebidas alcoólicas. O consumo de álcool também é comum entre menores de 18 anos, apesar de a venda ser proibida em todo o país. Os dados da Pesquisa Nacional de Saúde - PNS 2013, realizada pelo Instituto Brasileiro de Geografia e Estatística - IBGE, mostrou que 21,9\% dos adolescentes consegue comprar álcool por conta própria. As informações da Pesquisa Nacional de Saúde Escolar (PENSE), também realizada pelo IBGE, indicaram que $9,9 \%$ dos jovens entrevistados nas capitais brasileiras e que frequentavam o $9^{\circ}$ ano escolar em 2012, já experimentaram algum tipo de droga ilícita, como maconha, cocaína, crack, etc. e, em 2009, esta proporção foi $8,7 \%$.

Neste mesmo sentido, o II Levantamento Nacional de Álcool e Drogas 2012 - LENAD (2014) coletou informações de 4.607 brasileiros. Os resultados foram comparados às informações coletadas em 2006, quando 3.007 brasileiros foram entrevistados, e apontam a vulnerabilidade dos jovens para o consumo de drogas. Entre os brasileiros adultos em 2006, 13\% haviam experimentado bebidas alcoólicas com menos de 15 anos. Em 2012, 22\% declarou ter experimentado com menos de 15 anos. A média de idade de experimentação do cigarro é em torno de 16 anos idade nos dois anos analisados.

1 O Observatório Brasileiro de Informações sobre Drogas (OBID) relata as várias doenças relacionadas ao consumo de diferentes tipos de drogas. Disponível em: http://www.obid.senad. gov.br/portais/OBID/index.php 
Do total de adolescentes entrevistados em 2012, 2,3\% já utilizou cocaína, 4,3\% utilizou maconha e 0,8\% utilizou crack.

Para orientar a elaboração de políticas para a prevenção do consumo de drogas por adolescentes, são necessárias evidências da relação entre os fatores de risco ${ }^{2}$ e a decisão de uso da droga, gerando uma demanda crescente por estudos científicos tanto na área da saúde como nas áreas das ciências sociais e humanas. Na literatura das ciências econômicas, tradicionalmente, os modelos de comportamento individual supõem que a decisão de participação em uma determinada atividade ou de consumo de um bem baseia-se em uma análise de custo-benefício, em que o indivíduo processa racionalmente as informações disponíveis, de modo a obter o melhor resultado de satisfação entre as possibilidades. Muitas vezes, as informações que os indivíduos utilizam para tomar decisões são obtidas observando o comportamento e as decisões dos demais indivíduos ao redor, principalmente quando se trata de jovens que não têm vivência suficiente para tomar decisões com base na própria experiência e, por isso, podem se espelhar no comportamento dos adultos ou adotar o comportamento prevalecente no grupo de indivíduos com idade similar, gerando um multiplicador comportamental (FREMANN, 1999).

Recentemente, foram desenvolvidos vários estudos com o intuito de formalizar a influência das relações sociais não mediadas pelo mercado no comportamento humano e na formação das preferências (COLEMAN, 1990; BANERJEE, 1992; BECKER, 1996). Em geral, as relações sociais são denominadas na literatura econômica como efeito par, multiplicador social/comportamental ou interações sociais. Também é comum utilizar o termo capital social, que Coleman (1990) definiu como os recursos que são inerentes às relações familiares e às organizações sociais da comunidade, e que são úteis para o desenvolvimento cognitivo e social de uma criança ou jovem.

Becker (1996) propôs incluir o componente capital social na função de utilidade, de modo que o comportamento individual seja determinado tanto pelos incentivos individuais como também pelo comportamento dos pares e pelas interações sociais que se estabelecem no ambiente de convívio do indivíduo. Segundo esta teoria, um aumento

2 A pesquisa do LENAD (2014) considera cinco grandes grupos de fatores de risco associados à decisão de uso de drogas, que são: saúde física, saúde mental, rede de suporte social (relações com familiares e amigos), eventos recentes (morte de membros da família ou problemas financeiros) e violência (urbana, na infância ou doméstica). 
no capital social de uma pessoa aumenta a demanda por produtos e atividades que são complementares a este capital e reduz a demanda por aqueles que são substitutos. Dessa forma, um adolescente pode começar a fumar, integrar-se a uma gangue ou negligenciar os seus estudos principalmente porque seus amigos fumam, são membros de gangues ou não prestam atenção às aulas.

Embora a importância do efeito das interações sociais sobre a decisão individual seja consensualmente reconhecida na literatura econômica recente, a magnitude desses efeitos ainda é controversa devido às dificuldades de estimação empírica, que serão discutidas na próxima seção. Além disso, poucos estudos dedicaram-se a estimar o efeito das interações sociais entre os jovens no Brasil, embora este grupo seja potencialmente suscetível aos efeitos das interações sociais por razões associadas à falta de experiência e à necessidade de se integrar e pertencer a um grupo, comportamentos característicos da idade. No caso específico do uso de substâncias ilícitas, não existem estudos na literatura nacional que mensurem empiricamente os fatores associados à decisão de consumo, embora este seja um tema de extrema relevância social e econômica em função do comprometimento físico e mental que o consumo de drogas pode causar ao indivíduo, onerando o sistema público de saúde e a formação do capital humano do país.

Diante disso, este estudo pretende avaliar a influência do efeito das interações sociais no ambiente escolar sobre as decisões de consumo dos jovens no que se refere ao uso de drogas ilícitas, álcool ou cigarro. Para isso, são realizadas estimativas de um modelo de consumo individual, utilizando instrumentos para o efeito interação social e um conjunto de variáveis de características da família, com base nas informações dos jovens do $9^{\circ}$ ano escolar que participaram do PENSE - 2012. Assim, além de disponibilizar evidências empíricas do efeito das interações sociais entre os jovens brasileiros, os resultados deste estudo podem contribuir para orientar políticas de prevenção ao consumo de drogas através da identificação, tanto da presença deste efeito nas relações que se estabelecem entre os alunos na escola e que influenciam a decisão individual de consumo de drogas, como também de alguns fatores de risco associados às famílias dos jovens. 


\section{O efeito da interação social nas decisões dos jovens}

O reconhecimento da influência da interação social sobre as decisões individuais desencadeou uma série de estudos teóricos e empíricos sobre o assunto. Manski (1993) identifica três hipóteses para explicar porque indivíduos em um mesmo grupo tendem a apresentar um comportamento similar. A primeira delas, denominada de efeito endógeno (endogenous effect), observa-se quando a probabilidade de o indivíduo se comportar de determinada forma varia conforme o comportamento do grupo. A segunda hipótese ocorre quando o comportamento do indivíduo é influenciado pelas características exógenas dos indivíduos que compõem o grupo, por isso denominase de efeito exógeno ou contextual (exogenous or contextual effect). Já a terceira, denominada de efeito correlação (correlated effect), refere-se à possibilidade de os indivíduos que compartilham o mesmo ambiente institucional apresentarem comportamentos similares porque estão, por exemplo, sujeitos às mesmas regras de convivência. Este último efeito é também denominado efeito espúrio, pois, caso as variáveis que caracterizam o ambiente institucional forem não observáveis, esse efeito pode ser facilmente confundido e erroneamente interpretado como efeito endógeno ou contextual.

O autor ainda apresenta um exemplo para ajudar a entender a distinção entre os três efeitos. Considerando a proficiência de um aluno, haverá um efeito endógeno se, tudo o mais constante, a proficiência do jovem variar conforme a média de proficiência dos alunos na turma. Haverá efeito exógeno se a proficiência variar conforme alguma característica média do grupo, como, por exemplo, a composição socioeconômica dos alunos da turma. Haverá efeito correlação se a similaridade de proficiência dos alunos da mesma turma decorrer do fato de serem ensinados pelo mesmo professor.

De maneira geral, os estudos empíricos concentram-se em identificar um dos dois primeiros efeitos, ou ambos, buscando, na medida do possível, controlar o efeito espúrio. Conforme Gaviria e Raphael (2001) os estudos que buscam identificar os efeitos contextuais refletem o interesse dos sociólogos nas características de circunstâncias e de convivência social (background), enquanto os que buscam identificar o efeito endógeno refletem o recorrente interesse dos economistas em externalidades. Para Brock e Durlauf (2007), o es- 
tudo das interações sociais integra tanto as ideias sociológicas como as econômicas.

Diante desta complexidade, a literatura está longe de ser conclusiva no que se refere à magnitude dos efeitos das interações sociais, uma vez que os problemas de endogeneidade ocasionados pela reciprocidade com a qual um indivíduo influencia e é influenciado pelos demais pode levar à superestimação do efeito dos pares. Além disso, é difícil identificar a importância relativa das várias formas de interação social vivenciada pelos jovens e muitos fatores importantes nesse processo podem não ser facilmente observados (ANGRIST, 2014).

$\mathrm{Na}$ tentativa de minimizar estas limitações, os estudos empíricos empregam diferentes técnicas de estimação. Bobonis e Finan (2009) utilizaram a evidência experimental do programa PROGRESA no México para identificar o efeito par da vizinhança na decisão de matricular nas escolas as crianças não elegíveis para o programa, mas que residiam nas comunidades de tratamento. Os resultados indicaram uma influência bastante considerável dos pares na decisão de matricular as crianças não elegíveis, principalmente nas famílias pobres, de modo que, segundo os autores, o programa produziu um efeito de multiplicador social.

Kremer e Levy (2008) estimaram o efeito dos pares em uma universidade estadual nos Estados Unidos que usa um sistema de sorteio para atribuir os colegas de quarto nas residências de estudantes. Os resultados indicaram que aqueles que foram designados para quartos onde os colegas consumiam álcool obtiveram uma nota média menor comparada à média de nota daqueles que foram designados para quartos onde os colegas não consumiam álcool. Porém, os resultados acadêmicos dos colegas de quarto ou o status socioeconômico não apresentaram efeito significativo sobre a média de notas.

Hanushek et al. (2003) utilizaram um painel de dados dos estudantes nas escolas do Texas, com efeito fixo para alunos e turmas e controles para as características observáveis da família e da escola. Para controlar também a natureza recíproca da interação social, os autores utilizaram a proficiência passada como medida de qualidade dos pares. Os resultados indicaram que, ao longo de toda a distribuição de notas, os alunos pareceram se beneficiar da maior proficiência 
dos colegas, de modo que os resultados dos pares tiveram um efeito positivo sobre o aumento da proficiência individual.

Angrist e Lang (2004) analisaram os efeitos do programa "Metropolitan Council for Educational Opportunity" (Metco), que consiste em enviar estudantes das escolas de Boston, negros na maioria, para escolas nos distritos dos arredores da cidade, onde a maioria dos estudantes é branca. Os dados no nível da escola e dos distritos não indicaram impacto do Metco sobre os resultados dos estudantes. Foram observadas evidências do efeito apenas para a terceira série, especialmente nas meninas. Porém, as estimativas utilizando variável instrumental foram imprecisas, o que levou os autores a concluir que o efeito par do Metco é modesto e de curta duração.

Duflo et al. (2011) analisaram um experimento realizado em escolas no Kenya, onde as crianças do grupo de tratamento foram agrupadas conforme a habilidade, mensurada através de um teste preliminar de proficiência, e as crianças das escolas de controle foram aleatorizadas em duas classes. $\mathrm{Na}$ análise dos resultados escolares das crianças nas escolas de controle, foi incluído o efeito par dos colegas de classe, que foi significativo apenas para os estudantes dos quartis superiores e inferiores dos resultados do teste preliminar. Porém, Angrist (2014) apontou possíveis problemas de mensuração, como o fato de os resultados do teste preliminar não poderem ser comparados entre as escolas, o que pode levar a divergência entre estimativas obtivas por Mínimos Quadrados Ordinários (MQO) e em Dois Estágios, (MQ2E).

Para identificar o efeito par sobre a proficiência em matemática dos alunos do $5^{\circ}$ ano em escolas no Brasil, Firpo et al. (2015) estimaram, em princípio, os coeficientes de uma equação de proficiência individual (within-regression) e de uma equação, considerando as médias das turmas como unidades de observação (between-regression). A partir destes coeficientes, os autores estimaram uma equação denominada de "linear-in-means", que relaciona a proficiência escolar com as características do aluno, do grupo e com o desempenho esperado dentro do grupo. 
Os resultados indicaram que o efeito contextual, observado através das características dos pares, como sexo, cor, idade e um índice socioeconômico, é um importante determinante do rendimento escolar dos estudantes. Destaca-se ainda que o sinal do efeito contextual da variável sexo feminino é o oposto do efeito desta variável no modelo individual. Em outras palavras, apesar de as meninas apresentarem pontuações médias mais baixas, um aumento na proporção de meninas na sala de aula tem um efeito positivo sobre o rendimento da classe. As estimativas do efeito endógeno foram aproximadamente 0,4 , o que os autores interpretaram como uma evidência de um "conformismo individual", no qual os alunos consideram custoso exercer níveis esforço além do que se acredita ser o padrão na sala de aula.

Os autores ainda consideram o fato de que, dado que a educação é um bem normal, as famílias em uma posição socioeconômica mais favorável poderiam pagar por uma educação de qualidade. Se este processo de autosseleção não puder ser controlado pela seleção em características observáveis, as estimativas podem ser viesadas. A estratégia dos autores foi utilizar a regra de alocação dos alunos entre as turmas por parte do diretor como um instrumento para controlar a endogeneidade das características dos pares. De maneira geral, as estimativas pontuais dos parâmetros mantiveram-se praticamente inalteradas, porém o coeficiente associado ao efeito endógeno não foi estatisticamente diferente de zero.

Além da proficiência escolar, a literatura analisa outras variáveis relacionadas aos jovens que podem sofrer influência do efeito interação. Bayer et al. (2009) analisaram a influência de menores infratores sobre o comportamento subsequente dos demais jovens cumprindo pena na mesma instituição através de um modelo de efeito fixo, usando apenas variação within (dentro da instituição) ao longo do tempo. Os resultados indicaram uma forte evidência do efeito dos pares sobre crimes como roubo, furto, tráfico de drogas e crimes sexuais.

Gaviria e Raphael (2001) analisaram efeito dos pares sobre a probabilidade de o jovem realizar as seguintes atividades: consumir drogas, álcool ou cigarros, frequentar a igreja e abandonar a escola. Os resultados indicaram a influência da interação social em todas as atividades e foram encontradas evidências de viés de endogeneidade. 
De maneira semelhante, Lundborg (2006) analisou a influência dos pares na escola sobre as decisões de consumo de álcool, cigarro e drogas ilícitas, através de um modelo de efeitos fixos para escolas e turmas. Os resultados também foram positivos e significativos para todas as atividades e, após controlar o viés de endogeneidade, os resultados do efeito par foram maiores. Powell et al. (2005) analisaram se o preço do cigarro e as políticas antitabagismo podem influenciar a demanda de cigarros dos jovens tanto de forma direta como de forma indireta, devido ao efeito par. Os resultados indicaram que existe um multiplicador social para qualquer mudança exógena nas taxas ou nas políticas de controle do tabaco.

\section{Método empírico}

A estratégia empírica é semelhante à utilizada por Gaviria e Raphael (2001), na qual se estima um modelo de comportamento individual, através da seguinte equação:

$$
Y_{i s}=\alpha+X_{i s} \beta+W_{s} \phi+\gamma \bar{Y}_{-i s}+\varepsilon_{i s}
$$

onde $Y_{i s}$ é uma variável binária com valor 1 se o estudante $i$, na escola $s$, consumiu $Y$ (drogas ilícitas, álcool ou cigarro) e zero caso contrário. $X_{i s}$ é o vetor de características individuais ou da família dos jovens, $W_{s}$ é o vetor de características de localização da escola, $\bar{Y}_{-i s}$ é a proporção de estudantes na escola $s$ que realizam o consumo de $Y$, excluindo o indivíduo $i, \varepsilon_{i s}$ é o erro aleatório e $\alpha, \beta, \phi$ e $\gamma$ são parâmetros. As estimativas são realizadas utilizando o estimador robusto de Huber-White, que considera a matriz de covariância residual agrupada por escola.

$\mathrm{Na}$ Equação (1) existem algumas potenciais fontes de viés de endogeneidade. Primeiro, embora a hipótese da Equação (1) seja de que o comportamento médio afeta o comportamento individual, o comportamento individual também pode afetar o comportamento médio. Como resultado, o termo do erro será correlacionado com $\bar{Y}_{-i s}$ e as estimativas por Mínimos Quadrados Ordinários (MQO) serão viesadas. 
Segundo, se uma variável relevante da escola for omitida, o termo do erro para as crianças na mesma escola será correlacionado e as estimativas de $M Q O$ para o efeito de interação social poderão ser viesadas. Por exemplo, se uma escola realiza programas de prevenção ao uso da droga, é possível que os jovens que frequentam esta escola sejam menos suscetíveis a experimentar esta substância. Se esta variável for omitida do modelo, o termo do erro dos alunos que frequentam esta escola será correlacionado, o que pode aviesar as estimativas do efeito interação.

Dessa forma, o efeito espúrio aumenta quando os jovens no mesmo grupo de referência agem de forma similar por compartilharem um conjunto de características não observáveis. Isso pode também ocorrer quando as famílias selecionam a escola com melhor capacidade de influenciar positivamente as crianças e, se esta consciência dos pais for não observada e ainda correlacionada com o comportamento médio do grupo, as estimativas de MQO para o efeito de interação social poderão ser superestimadas. Esta situação configura-se na terceira possível fonte de viés, relacionada à escolha endógena das escolas pelas famílias.

A estratégia para lidar com primeira fonte de viés é encontrar um conjunto de variáveis que possam ser utilizadas como instrumentos para o efeito de interação, ou seja, correlacionadas com $\bar{Y}_{-i s}$ e não correlacionadas com o erro. Conforme Gaviria e Raphael (2001), sob a hipótese de ausência de relação direta entre o resultado individual $i$ e a média de características das famílias dos colegas do indivíduo $i, \bar{X}_{-i s}$ fornece um conjunto de instrumentos naturalmente válido para o comportamento médio do grupo. Essa hipótese é razoável se considerar que, na escola, as crianças não convivem diretamente com os pais dos seus colegas, logo, o efeito de interação social estimado reflete a influência do comportamento que prevalece no grupo de jovens que interagem na escola. Por exemplo, se os pais dos colegas de um jovem usam drogas, isso pode afetar a probabilidade individual de consumir drogas devido ao aumento na probabilidade de os colegas usarem drogas.

Sob estas condições, podemos definir a equação do primeiro estágio:

$$
\bar{Y}_{-i s}=\alpha^{\prime}+\bar{X}_{-i s} \gamma^{\prime}+W_{s} \phi^{\prime}+u_{i s}
$$


Esta equação também pode ser chamada de modelo na forma reduzida, e apresenta apenas regressores exógenos do lado direito. $\bar{X}_{-i s}$ são os instrumentos de $\bar{Y}_{-i s}$, não correlacionados com o erro da Equação (1) do modelo estrutural, ou seja:

$$
E\left(\varepsilon_{i s} \mid \bar{X}_{-i s}\right)=0
$$

A condição (3) pode ser testada em modelos sobreidentificados, ou seja, quando o número de instrumentos disponíveis é maior que o número de variáveis endógenas, através do teste de sobreidentificação das restrições, cuja hipótese nula supõe ausência de correlação entre os instrumentos e o erro da equação. Porém, mesmo quando a realização do teste é possível, a validade dos instrumentos deve sustentar-se de forma teórica, empírica ou intuitiva.

Além disso, para identificação do modelo, é importante garantir que os instrumentos selecionados $\bar{X}_{-i s}$ sejam relevantes, ou seja, apresentem uma forte associação com $\bar{Y}_{-i s}$. Embora o método de variáveis instrumentais produzam estimativas consistentes, na presença de instrumentos fracos estas estimativas podem ser menos precisas, com erros padrão maiores se comparadas às estimações por MQO. Uma forma de testar se os instrumentos são fracos é realizar o teste de significância conjunta dos instrumentos no primeiro estágio da regressão.

Neste estudo foram selecionadas sete variáveis de características médias das famílias dos colegas do indivíduo $i$ para compor o conjunto de instrumentos $\bar{X}_{-i s}$. Três variáveis referem-se às características médias dos pais dos pares, que são: a proporção de colegas que ao menos um dos pais tem faculdade, que um dos pais fuma e que pertencem a uma família uniparental. Outras duas variáveis referemse às médias de participação e supervisão dos pais dos colegas nas atividades do cotidiano dos filhos, que são: a proporção de pais que verificam a lição de casa e que realizam as refeições com seus filhos. As duas últimas variáveis referem-se à média de pais dos colegas que tem atitudes permissivas em relação ao consumo de substâncias ilícitas por seus filhos, que são: proporção de pais que não se importam de o filho fumar e que não se importam de o filho beber.

O argumento para considerar tais variáveis como potenciais instrumentos é que a estrutura da família, o exemplo de conduta, o envolvimento e o controle dos pais afetam o comportamento dos 
filhos, mas não afetam diretamente o comportamento dos colegas dos filhos. Porém, se, por exemplo, os colegas de um jovem fazem uso do álcool porque seus respectivos pais são permissivos em relação ao consumo desta substância, isso pode afetar a probabilidade deste jovem também fazer uso do álcool por influência dos colegas, como uma forma de se integrar ao grupo. Este mesmo conjunto de instrumentos pode ser utilizado para corrigir uma possível omissão de uma variável relevante da escola sob a hipótese de que este atributo escolar não é sistematicamente correlacionado com a média de condições socioeconômicas do corpo discente da escola.

No caso da última fonte de viés, relacionada à escolha endógena das escolas pelas famílias, é possível que este problema não seja tão grave neste estudo devido à utilização de controles para o envolvimento dos pais com as atividades dos filhos, que funcionariam como uma medida para a conscientização dos pais. Mesmo assim, na tentativa de avaliar a dimensão com a qual as estimativas do efeito interação estariam distorcidas pela escolha endógena das escolas, propõe-se um exercício empírico.

Parte-se da hipótese de que os pais mais preocupados com ambiente em que seus filhos estão expostos selecionariam as escolas em áreas seguras. Para que esta escolha dos pais não seja limitada pelas condições financeiras da família, foi selecionada uma amostra de alunos em escolas privadas com mensalidade superior a $R \$ 662,00$, que é aproximadamente o valor do salário mínimo de $\mathrm{R} \$ 622,00$ no ano de 2012. Como a fonte dos dados utilizada neste estudo, descrita no próximo item, disponibiliza o valor da mensalidade por faixas, a faixa imediatamente superior ao valor do salário mínimo em 2012 tem como intervalo inferior ao valor de $\mathrm{R} \$ 662,00$. Dessa forma, foram selecionadas famílias com condições de comprometer mais de um salário mínimo na educação dos filhos.

Em seguida, esta amostra foi subdividida em dois grupos, um de escolas situadas em área de risco em termos de violência (roubos, furtos, assaltos, troca de tiros, homicídios, etc.) e outro de escolas que não se localizam em áreas de risco. Sob a hipótese de que os pais mais preocupados selecionariam as escolas em áreas seguras, haveria uma correlação entre a conscientização não observada dos pais e o comportamento médio do grupo de alunos nestas escolas e, consequentemente, o efeito de interação social deveria ser maior para este 
grupo em comparação aos resultados do grupo de jovens em escolas localizadas em áreas de risco. Dessa forma, o ambiente no entorno da escola seria uma forma indireta de avaliar o viés relacionado à escolha endógena dos pais.

\subsection{Dados}

Os dados são da Pesquisa Nacional de Saúde do Escolar (PENSE), ${ }^{3}$ realizada em 2012 pelo IBGE, com o objetivo de ampliar o conhecimento sobre a saúde dos adolescentes e subsidiar as políticas públicas relativas a este grupo. A partir de uma amostra de escolas, foram coletadas informações de diversos fatores de risco à saúde, além das condições socioeconômicas dos estudantes do $9^{\circ}$ ano $\left(8^{\mathrm{a}}\right.$ série$)$ do ensino fundamental. Também foram coletadas informações básicas das escolas, fornecidas pelos diretores das unidades selecionadas. A escolha do $9^{\circ}$ ano do ensino fundamental teve como justificativas o mínimo de escolarização considerada necessária para responder ao questionário autoaplicável e também a proximidade da idade de referência preconizada pela Organização Mundial da Saúde - OMS, que é de 13 a 15 anos (IBGE, 2013).

Para compor a amostra, primeiramente, foi realizada uma estratificação do território nacional, onde cada um dos 26 municípios das capitais e o Distrito Federal foi definido como um estrato geográfico e os demais municípios foram agrupados nas Grandes Regiões a que pertencem, formando mais cinco estratos geográficos. Em cada um dos estratos, foi dimensionada e selecionada uma amostra a partir do cadastro de escolas do ensino fundamental listadas no Censo Escolar de 2010, realizado pelo Instituto Nacional de Estudos e Pesquisas Educacionais Anísio Teixeira - INEP. Em seguida, foi selecionada uma amostra de turmas em cada escola e os respectivos alunos foram convidados a responder o questionário da pesquisa. Assim, foi obtida uma amostra de 109.104 alunos em 2.842 escolas.

\footnotetext{
3 Maiores informações estão disponíveis em: http://www.ibge.gov.br/home/estatistica/populacao/pense/2012/default.shtm
} 


\subsection{Definição das variáveis e estatísticas descritivas}

Neste estudo foram utilizados os dados do PENSE para jovens com idade entre 12 e 17 anos, totalizando 84.865 alunos em 2.234 escolas públicas e 22.443 alunos em 608 escolas privadas. A Tabela 1 apresenta a definição e as estatísticas descritivas das três variáveis dependentes, construídas a partir das informações do questionário socioeconômico dos alunos. O consumo de álcool é o mais frequente entre os jovens, observado em $65 \%$ dos alunos em escolas públicas e $71 \%$ em escolas privadas, seguido do consumo de cigarros, em que estes valores são $21 \%$ e $14 \%$, respectivamente e, por fim, o consumo de drogas ilícitas é observado em $7 \%$ dos jovens em escolas públicas e $6 \%$ em escolas privadas.

Tabela 1 - Definição das variáveis de consumo, $Y$, e estatísticas descritivas

\begin{tabular}{|c|c|c|c|c|c|}
\hline \multirow{2}{*}{ Variável } & \multirow{2}{*}{ Definição } & \multicolumn{2}{|c|}{ Pública } & \multicolumn{2}{|c|}{ Privada } \\
\hline & & amostra & média & amostra & média \\
\hline Droga & $\begin{array}{l}\text { binária igual a } 1 \text { se o jovem usou alguma droga, } \\
\text { tais como: maconha, cocaína, crack, ecstasy, } \\
\text { etc. e igual a } 0 \text { caso contrário. }\end{array}$ & 84.666 & $\begin{array}{l}0,071 \\
(0,257)\end{array}$ & 22.405 & $\begin{array}{c}0,063 \\
(0,242)\end{array}$ \\
\hline Álcool & $\begin{array}{l}\text { binária igual a } 1 \text { se o jovem já experimentou be- } \\
\text { bida alcoólica e igual a } 0 \text { caso contrário. }\end{array}$ & 84.692 & $\begin{array}{l}0,656 \\
(0,475)\end{array}$ & 22.411 & $\begin{array}{c}0,713 \\
(0,452)\end{array}$ \\
\hline Cigarro & $\begin{array}{l}\text { binária igual a } 1 \text { se o jovem você já fumou } \\
\text { cigarro e igual a } 0 \text { caso contrário. }\end{array}$ & 84.707 & $\begin{array}{c}0,206 \\
(0,404)\end{array}$ & 22.411 & $\begin{array}{l}0,137 \\
(0,344)\end{array}$ \\
\hline
\end{tabular}

Fonte: Elaboração do autor com base nos microdados do PENSE, 2012.

Nota: As observações foram ponderadas pelo fator de expansão da amostra. Desvio-padrão entre parênteses.

A Tabela 2 apresenta a descrição, a média e o desvio padrão das variáveis de controle do modelo de comportamento individual de consumo, representado na Equação (1). Estas variáveis podem ser agrupadas em três categorias: variáveis pessoais, variáveis de características socioeconômicas da família e envolvimento dos pais com a vida dos filhos e variáveis de localização das escolas.

As variáveis pessoais são o sexo, a cor e a idade do jovem e também o fato de ele trabalhar. Há mais jovens que se autodeclararam não brancos nas escolas públicas, $66 \%$, enquanto nas escolas privadas este valor é $47 \%$. Do total dos jovens nas escolas públicas, 13,7\% trabalham e, nas escolas privadas, este valor é 8,5\%. 
Tabela 2 - Definição das variáveis de controle e estatísticas descritivas

\begin{tabular}{|c|c|c|c|}
\hline \multirow{2}{*}{ Variável } & \multirow{2}{*}{ Descrição } & \multicolumn{2}{|c|}{ Média } \\
\hline & & Pública & Privada \\
\hline Meninos & $\begin{array}{l}\text { binária igual a } 1 \text { se o jovem é do sexo masculino e } \\
\text { igual a } 0 \text { se é do sexo feminino. }\end{array}$ & $\begin{array}{c}0,473 \\
(0,003)\end{array}$ & $\begin{array}{c}0,492 \\
(0,010)\end{array}$ \\
\hline Não brancos & $\begin{array}{l}\text { binária igual a } 1 \text { se o jovem é não branco e igual a } 0 \\
\text { caso contrário. }\end{array}$ & $\begin{array}{c}0,663 \\
(0,005)\end{array}$ & $\begin{array}{c}0,471 \\
(0,013)\end{array}$ \\
\hline Idade & Idade - entre 12 e 17 anos & $\begin{array}{l}14,280 \\
(0,015)\end{array}$ & $\begin{array}{l}13,889 \\
(0,018)\end{array}$ \\
\hline Trabalha & $\begin{array}{l}\text { binária igual a } 1 \text { se o jovem trabalha e igual a } 0 \text { caso } \\
\text { contrário }\end{array}$ & $\begin{array}{l}0,137 \\
(0,002)\end{array}$ & $\begin{array}{l}0,085 \\
(0,004)\end{array}$ \\
\hline Nível de vida & $\begin{array}{l}\text { Indicador construído pelo método de componentes } \\
\text { principais. }\end{array}$ & $\begin{array}{c}0,216 \\
(0,019)\end{array}$ & $\begin{array}{l}0,796 \\
(0,017)\end{array}$ \\
\hline $\begin{array}{l}\text { Um dos pais tem fa- } \\
\text { culdade }\end{array}$ & $\begin{array}{l}\text { binária igual a } 1 \text { se ao menos um dos pais tem facul- } \\
\text { dade e igual a } 0 \text { caso contrário }\end{array}$ & $\begin{array}{l}0,077 \\
(0,002)\end{array}$ & $\begin{array}{l}0,403 \\
(0,016)\end{array}$ \\
\hline Família uniparental & $\begin{array}{l}\text { binária igual a } 1 \text { se o jovem não mora com um dos } \\
\text { pais e igual a } 0 \text { caso contrário (c. c.) }\end{array}$ & $\begin{array}{c}0,390 \\
(0,004)\end{array}$ & $\begin{array}{c}0,313 \\
(0,006)\end{array}$ \\
\hline $\begin{array}{l}\text { Pais não ajudam no } \\
\text { dever de casa }\end{array}$ & $\begin{array}{l}\text { binária igual a } 1 \text { se os pais nunca ou raramente } \\
\text { verificam o dever de casa e } 0 \text { c. c. }\end{array}$ & $\begin{array}{c}0,423 \\
(0,003)\end{array}$ & $\begin{array}{l}0,503 \\
(0,008)\end{array}$ \\
\hline Não almoça com os pais & $\begin{array}{l}\text { binária igual a } 1 \text { se o jovem nunca ou raramente } \\
\text { almoça/janta com os pais e } 0 \text { c. c. }\end{array}$ & $\begin{array}{c}0,243 \\
(0,003)\end{array}$ & $\begin{array}{l}0,201 \\
(0,006)\end{array}$ \\
\hline Um dos pais fuma & $\begin{array}{l}\text { binária igual a } 1 \text { se um dos pais fuma e igual a } 0 \text { caso } \\
\text { contrário }\end{array}$ & $\begin{array}{c}0,312 \\
(0,003)\end{array}$ & $\begin{array}{c}0,182 \\
(0,005)\end{array}$ \\
\hline Pais deixam fumar & $\begin{array}{l}\text { binária igual a } 1 \text { se a família não se importa caso o } \\
\text { jovem fume ou venha a fumar e } 0 \text { c. c. }\end{array}$ & $\begin{array}{l}0,055 \\
(0,001)\end{array}$ & $\begin{array}{c}0,026 \\
(0,002)\end{array}$ \\
\hline Pais deixam beber & $\begin{array}{l}\text { binária igual a } 1 \text { se a família não se importa caso } 0 \\
\text { jovem fique bêbado e } 0 \text { caso contrário }\end{array}$ & $\begin{array}{c}0,046 \\
(0,001)\end{array}$ & $\begin{array}{c}0,025 \\
(0,002)\end{array}$ \\
\hline Capital & $\begin{array}{l}\text { binária igual a } 1 \text { se a escola localiza-se na capital do } \\
\text { estado }\end{array}$ & $\begin{array}{c}0,204 \\
(0,012)\end{array}$ & $\begin{array}{c}0,332 \\
(0,028)\end{array}$ \\
\hline \multicolumn{4}{|l|}{ Base (Nordeste) } \\
\hline Norte & & $\begin{array}{c}0,084 \\
(0,005)\end{array}$ & $\begin{array}{c}0,045 \\
(0,007)\end{array}$ \\
\hline Sudeste & $\begin{array}{l}\text { Foram definidas } 4 \text { binárias para diferenciar as } 5 \text { re- } \\
\text { giões geográficas do país, onde a categoria base é a }\end{array}$ & $\begin{array}{c}0,424 \\
(0,019)\end{array}$ & $\begin{array}{c}0,563 \\
(0,033)\end{array}$ \\
\hline Sul & $\begin{array}{l}\text { gloes geogranicas do pals, onde a categoria base e a } \\
\text { região Nordeste. }\end{array}$ & $\begin{array}{c}0,159 \\
(0,011)\end{array}$ & $\begin{array}{c}0,093 \\
(0,016)\end{array}$ \\
\hline Centro-Oeste & & $\begin{array}{c}0,081 \\
(0,006)\end{array}$ & $\begin{array}{l}0,068 \\
(0,009)\end{array}$ \\
\hline
\end{tabular}

Nota: Ponderação pelo fator de expansão da amostra (Pense, 2012). Desvio padrão entre parênteses.

Os jovens que compõem a amostra têm em média 14 anos, que é a idade regular dos alunos no $9^{\circ}$ ano. Assim, a amostra é composta por três grupos de estudantes: os que estão em idade regular, com 14 anos, os que estão adiantados, entre 12 e 13 anos, e os que estão atrasados no sistema educacional, entre 15 e 17 anos. A Tabela 3 mostra que existe uma diferença na média de consumo de subs- 
tâncias ilícitas entre estes grupos, onde a proporção de alunos que fizeram uso de tais substâncias é maior entre os que estão atrasados e menor entre os que estão adiantados, ambos em relação aos alunos em idade regular.

Além disso, é possível observar que existe uma diferença entre as médias de consumo nas escolas públicas (Pub.) e privadas (Priv.) estatisticamente significativa a, no mínimo, 5\%, com exceção apenas do consumo de cigarros dos alunos com mais de 14 anos. Dessa forma, é possível que o comportamento dos alunos e as interações sociais sejam distintas tanto entre grupos de idade dos alunos no $9^{\circ}$ ano como também entre os alunos que frequentam escolas públicas e privadas.

Tabela 3 - Média de consumo de drogas por categorias de idade

\begin{tabular}{lccccccccc}
\hline & \multicolumn{2}{c}{ Droga } & \multicolumn{4}{c}{ Álcool } & \multicolumn{4}{c}{ Cigarro } \\
& Pub. & Priv. & $t$ & Pub. & Priv. & $t$ & Pub. & Priv. & $t$ \\
\hline Regular & 0,065 & 0,057 & $(3,0)$ & 0,646 & 0,727 & $(-16,7)$ & 0,197 & 0,132 & $(16,2)$ \\
$(14$ anos $)$ & & & & & & & & & \\
Adiantado & 0,044 & 0,038 & $(2,2)$ & 0,595 & 0,661 & $(-9,3)$ & 0,148 & 0,090 & $(11,8)$ \\
$(<14$ anos $)$ & $(9,2)$ & $(5,8)$ & & $(11,2)$ & $(9,6)$ & & $(13,3)$ & $(8,7)$ & \\
Atrasados & 0,114 & 0,160 & $(-7,7)$ & 0,700 & 0,818 & $(-14,2)$ & 0,296 & 0,304 & $(-0,9)$ \\
$(>14$ anos $)$ & $(-23,0)$ & $(-19,6)$ & & $(-14,9)$ & $(-10,7)$ & & $(-30,6)$ & $(-23,9)$ & \\
\hline
\end{tabular}

Nota: Ponderação pelo fator de expansão da amostra (Pense, 2012). Estatística $t$ entre parênteses para a diferença de médias.

Foram também definidas variáveis das características das famílias dos jovens. A primeira delas é um indicador do nível de vida, construído utilizando o método de componentes principais das correlações simples de 5 variáveis que representam a existência ou não de bens na residência dos jovens (Tabela 4). O primeiro componente principal foi definido como a variável nível de vida, uma vez que explica aproximadamente $37 \%$ da variância total dos dados nas escolas públicas e 33\% nas escolas privadas. A Tabela 4 apresenta os autovetores (ou coeficientes das combinações lineares), obtidos a partir da matriz de correlação das variáveis originais, que indicam qual a importância de cada uma das variáveis no primeiro componente principal. 
Tabela 4 - Análise de componentes principais dos bens na residência dos alunos

\begin{tabular}{lcc}
\hline Variáveis & Pública & Autovetor \\
& 0,3694 & Privada \\
\hline Telefone fixo & 0,5609 & 0,371 \\
Computador & 0,5547 & 0,5433 \\
Internet & 0,3848 & 0,5497 \\
Carro & 0,2642 & 0,4125 \\
Empregada & 2,25153 & 0,1371 \\
\hline Autovalor & 0,3753 & 1,96011 \\
Variância Proporcional & 0,3267 \\
\hline
\end{tabular}

Fonte: Elaboração do autor com base nos microdados do PENSE, 2012.

Além do nível de vida, a categoria das características da família inclui sete variáveis referentes ao comportamento e ao envolvimento dos pais nas atividades dos filhos que são: se ao menos um dos pais tem faculdade, se a família é uniparental, se os pais verificam a lição de casa, se o jovem realiza as refeições com os pais, se um dos pais fuma, se os pais não se importam de o jovem fumar e se os pais não se importam de o jovem beber. Todas estas informações foram obtidas no questionário dos alunos, ou seja, são baseadas nas declarações dos jovens. Chama a atenção que apenas para $7,7 \%$ dos jovens em escolas públicas o pai ou a mãe completou a faculdade, enquanto nas escolas privadas este valor é 40,3\% (Tabela 2).

Quanto às características de localização das escolas, podemos observar que a maioria dos alunos que compõem a amostra residem na região Sudeste, $42 \%$ dos alunos de escolas públicas e $56 \%$ de escolas privadas. Do total de alunos observados nas escolas públicas, $20 \%$ residem em capitais e, nas escolas privadas, esta proporção é $33 \%$. 


\section{Resultados}

Os resultados das estimativas de Mínimos Quadrados em Dois Estágios (MQ2E) para as três categorias de consumo, drogas, álcool e cigarros estão, respectivamente, nas Tabelas 5,6 e 7 . As informações referem-se aos alunos do $9^{\circ}$ ano que tem idade regular (14 anos), que estão adiantados (com 12 e 13 anos) e que estão atrasados no sistema educacional (com idade entre 15 e 17 anos), em escolas públicas e privadas.

Os instrumentos utilizados para o efeito médio dos pares foram sete variáveis de características médias das famílias dos colegas do jovem. ${ }^{4}$ Nas últimas linhas das Tabelas 5, 6 e 7 estão os resultados dos testes de significância conjunta dos instrumentos no primeiro estágio da regressão (estatística $F$ ) e de sobreidentificação das restrições, cuja hipótese nula supõe ausência de correlação entre os instrumentos e o erro da equação (estatística $\chi^{2}$ ). A hipótese de ausência de significância conjunta dos instrumentos foi facilmente rejeitada. A falha em rejeitar a sobreidentificação das restrições foi possível em todas as equações, com exceção do modelo para o consumo de drogas e cigarros com informações dos jovens entre 15 e 17 anos de idade e para o consumo de álcool dos alunos em escolas públicas. Mesmo assim, para a maioria das equações consideradas, os resultados dos testes indicam a validade da escolha dos instrumentos.

4 Proporção de colegas que ao menos um dos pais tem faculdade, que a família é uniparental, que os pais verificam a lição de casa, que realizam as refeições com os pais, que um dos pais fuma, que os pais não se importam de o filho fumar e que os pais não se importam de o filho beber. 
Tabela 5 - Estimativas por $M Q 2 E$ para o consumo de drogas

\begin{tabular}{|c|c|c|c|c|c|c|}
\hline & \multicolumn{3}{|c|}{ Escola Pública } & \multicolumn{3}{|c|}{ Escola Privada } \\
\hline & 14 & $<14$ & $>14$ & 14 & $<14$ & $>14$ \\
\hline Efeito interação (MQO) & $\begin{array}{c}0,375^{\star \star *} \\
(0,033)\end{array}$ & $\begin{array}{c}0,229^{\star \star *} \\
(0,047)\end{array}$ & $\begin{array}{c}0,558^{\star * *} \\
(0,047)\end{array}$ & $\begin{array}{c}0,339^{* * *} \\
(0,050)\end{array}$ & $\begin{array}{c}0,215^{\star \star *} \\
(0,056)\end{array}$ & $\begin{array}{c}0,879^{* * *} \\
(0,134)\end{array}$ \\
\hline Efeito interação (MQ2E) & $\begin{array}{c}0,433^{\star \star \star} \\
(0,080)\end{array}$ & $\begin{array}{c}0,353^{\star \star \star} \\
(0,112)\end{array}$ & $\begin{array}{c}0,603^{\star \star \star} \\
(0,100)\end{array}$ & $\begin{array}{c}0,457^{\star \star \star} \\
(0,112)\end{array}$ & $\begin{array}{c}0,421^{\star \star *} \\
(0,140)\end{array}$ & $\begin{array}{l}0,727^{\star \star} \\
(0,327)\end{array}$ \\
\hline Meninos & $\begin{array}{l}-0,004 \\
(0,003)\end{array}$ & $\begin{array}{c}0,002 \\
(0,004)\end{array}$ & $\begin{array}{c}0,023^{\star \star \star} \\
(0,005)\end{array}$ & $\begin{array}{c}0,002 \\
(0,005)\end{array}$ & $\begin{array}{c}0,004 \\
(0,005)\end{array}$ & $\begin{array}{l}0,027^{*} \\
(0,016)\end{array}$ \\
\hline Não brancos & $\begin{array}{c}0,004 \\
(0,003)\end{array}$ & $\begin{array}{c}0,002 \\
(0,004)\end{array}$ & $\begin{array}{c}0,004 \\
(0,005)\end{array}$ & $\begin{array}{c}0,015^{\star \star \star} \\
(0,006)\end{array}$ & $\begin{array}{c}0,018^{\star \star \star} \\
(0,005)\end{array}$ & $\begin{array}{c}0,001 \\
(0,015)\end{array}$ \\
\hline Idade & & $\begin{array}{l}0,013^{*} \\
(0,007)\end{array}$ & $\begin{array}{c}0,015^{\star \star *} \\
(0,003)\end{array}$ & & $\begin{array}{c}0,000 \\
(0,011)\end{array}$ & $\begin{array}{c}0,044^{* * *} \\
(0,014)\end{array}$ \\
\hline Trabalha & $\begin{array}{c}0,045^{\star \star \star} \\
(0,006)\end{array}$ & $\begin{array}{c}0,036^{\star * *} \\
(0,008)\end{array}$ & $\begin{array}{c}0,042^{\star \star \star} \\
(0,006)\end{array}$ & $\begin{array}{c}0,016 \\
(0,012)\end{array}$ & $\begin{array}{c}0,056^{\star \star *} \\
(0,020)\end{array}$ & $\begin{array}{c}0,059^{* \star *} \\
(0,023)\end{array}$ \\
\hline Índice do nível de vida & $\begin{array}{l}0,002^{* *} \\
(0,001)\end{array}$ & $\begin{array}{c}0,002 \\
(0,001)\end{array}$ & $\begin{array}{c}0,005^{\star \star \star} \\
(0,002)\end{array}$ & $\begin{array}{c}0,004 \\
(0,003)\end{array}$ & $\begin{array}{l}-0,000 \\
(0,003)\end{array}$ & $\begin{array}{l}0,017^{\star *} \\
(0,007)\end{array}$ \\
\hline Um dos pais com faculdade & $\begin{array}{l}0,011^{* *} \\
(0,005)\end{array}$ & $\begin{array}{c}0,006 \\
(0,006)\end{array}$ & $\begin{array}{l}0,020^{* *} \\
(0,008)\end{array}$ & $\begin{array}{c}0,001 \\
(0,006)\end{array}$ & $\begin{array}{l}0,009^{\star} \\
(0,006)\end{array}$ & $\begin{array}{l}0,031^{* *} \\
(0,015)\end{array}$ \\
\hline Família uniparental & $\begin{array}{c}0,015^{\star \star *} \\
(0,003)\end{array}$ & $\begin{array}{c}0,013^{* * *} \\
(0,004)\end{array}$ & $\begin{array}{c}0,016^{* * *} \\
(0,004)\end{array}$ & $\begin{array}{c}0,014^{* \star *} \\
(0,005)\end{array}$ & $\begin{array}{l}-0,005 \\
(0,006)\end{array}$ & $\begin{array}{c}0,051^{* * *} \\
(0,016)\end{array}$ \\
\hline Pais não ajudam no dever & $\begin{array}{c}0,022^{\star \star \star} \\
(0,003)\end{array}$ & $\begin{array}{c}0,014^{\star * *} \\
(0,004)\end{array}$ & $\begin{array}{l}0,048^{\star \star \star} \\
(0,004)\end{array}$ & $\begin{array}{l}0,014^{\star \star \star} \\
(0,005)\end{array}$ & $\begin{array}{l}0,011^{*} \\
(0,006)\end{array}$ & $\begin{array}{l}0,031^{* *} \\
(0,015)\end{array}$ \\
\hline Não almoça com pais & $\begin{array}{c}0,025^{\star \star \star} \\
(0,004)\end{array}$ & $\begin{array}{c}0,019^{\star * *} \\
(0,005)\end{array}$ & $\begin{array}{c}0,027^{\star \star \star} \\
(0,005)\end{array}$ & $\begin{array}{c}0,033^{* \star \star} \\
(0,008)\end{array}$ & $\begin{array}{c}0,025^{\star \star *} \\
(0,008)\end{array}$ & $\begin{array}{l}0,035^{\star *} \\
(0,017)\end{array}$ \\
\hline Um dos pais fuma & $\begin{array}{c}0,022^{\star * *} \\
(0,004)\end{array}$ & $\begin{array}{c}0,018^{* * *} \\
(0,005)\end{array}$ & $\begin{array}{c}0,043^{* * *} \\
(0,005)\end{array}$ & $\begin{array}{c}0,021^{* * *} \\
(0,007)\end{array}$ & $\begin{array}{c}0,025^{\star * *} \\
(0,008)\end{array}$ & $\begin{array}{c}0,030 \\
(0,019)\end{array}$ \\
\hline Pais deixam fumar & $\begin{array}{c}0,002 \\
(0,011)\end{array}$ & $\begin{array}{c}0,010 \\
(0,018)\end{array}$ & $\begin{array}{c}0,013 \\
(0,011)\end{array}$ & $\begin{array}{c}0,079^{* * *} \\
(0,027)\end{array}$ & $\begin{array}{l}0,069^{\star} \\
(0,040)\end{array}$ & $\begin{array}{c}0,049 \\
(0,048)\end{array}$ \\
\hline Pais deixam beber & $\begin{array}{c}0,100^{\star \star *} \\
(0,018)\end{array}$ & $\begin{array}{c}0,089^{* * *} \\
(0,022)\end{array}$ & $\begin{array}{c}0,124^{\star \star \star} \\
(0,014)\end{array}$ & $\begin{array}{c}0,065^{\star \star \star} \\
(0,025)\end{array}$ & $\begin{array}{c}0,118^{\star \star *} \\
(0,044)\end{array}$ & $\begin{array}{l}0,146^{\star * *} \\
(0,045)\end{array}$ \\
\hline Capital & $\begin{array}{l}0,008^{\star} \\
(0,004)\end{array}$ & $\begin{array}{c}0,001 \\
(0,006)\end{array}$ & $\begin{array}{c}0,037^{\star * *} \\
(0,007)\end{array}$ & $\begin{array}{c}0,005 \\
(0,005)\end{array}$ & $\begin{array}{l}-0,001 \\
(0,006)\end{array}$ & $\begin{array}{c}0,034 \\
(0,021)\end{array}$ \\
\hline Base (NE) & & & & & & \\
\hline $\mathrm{N}$ & $\begin{array}{l}-0,001 \\
(0,003)\end{array}$ & $\begin{array}{l}-0,007 \\
(0,005)\end{array}$ & $\begin{array}{c}-0,01^{* * *} \\
(0,004)\end{array}$ & $\begin{array}{l}-0,006 \\
(0,005)\end{array}$ & $\begin{array}{l}0,013^{*} \\
(0,007)\end{array}$ & $\begin{array}{c}0,009 \\
(0,022)\end{array}$ \\
\hline SE & $\begin{array}{l}0,009^{* *} \\
(0,004)\end{array}$ & $\begin{array}{c}0,005 \\
(0,007)\end{array}$ & $\begin{array}{l}0,011^{*} \\
(0,006)\end{array}$ & $\begin{array}{l}0,015^{\star *} \\
(0,007)\end{array}$ & $\begin{array}{l}-0,002 \\
(0,008)\end{array}$ & $\begin{array}{c}0,016 \\
(0,024)\end{array}$ \\
\hline S & $\begin{array}{c}0,029^{\star \star *} \\
(0,007)\end{array}$ & $\begin{array}{c}0,002 \\
(0,008)\end{array}$ & $\begin{array}{c}0,055^{* * *} \\
(0,010)\end{array}$ & $\begin{array}{c}0,044^{* * *} \\
(0,012)\end{array}$ & $\begin{array}{c}0,011 \\
(0,009)\end{array}$ & $\begin{array}{c}0,172^{* * *} \\
(0,060)\end{array}$ \\
\hline $\mathrm{CO}$ & $\begin{array}{l}0,008^{\star} \\
(0,005)\end{array}$ & $\begin{array}{c}0,006 \\
(0,007)\end{array}$ & $\begin{array}{c}0,027^{* * *} \\
(0,007)\end{array}$ & $\begin{array}{l}0,018^{* *} \\
(0,008)\end{array}$ & $\begin{array}{l}0,015^{\star} \\
(0,008)\end{array}$ & $\begin{array}{c}0,021 \\
(0,027)\end{array}$ \\
\hline Constante & $\begin{array}{c}-0,021^{* \star *} \\
(0,005)\end{array}$ & $\begin{array}{l}-0,18^{\star \star} \\
(0,089)\end{array}$ & $\begin{array}{c}-0,28^{\star \star \star} \\
(0,051)\end{array}$ & $\begin{array}{c}-0,03^{\star \star \star} \\
(0,008)\end{array}$ & $\begin{array}{l}-0,030 \\
(0,148)\end{array}$ & $\begin{array}{c}-0,732^{\star \star \star} \\
(0,218)\end{array}$ \\
\hline Observações & 37.841 & 15.430 & 29.979 & 12.335 & 6.683 & 3.273 \\
\hline Escolas & 2.216 & 2.068 & 2.218 & 606 & 605 & 571 \\
\hline$R^{2}$ & 0,0349 & 0,0244 & 0,0692 & 0,0310 & 0,0340 & 0,0833 \\
\hline $\mathrm{F}$ & 19,35 & 15,57 & 16,89 & 8,37 & 6,61 & 6,54 \\
\hline$\chi^{2}$ & 6,6595 & 6,0264 & 10,7265 & 2,4714 & 3,0795 & 19,464 \\
\hline Valor $p$ & 0,3535 & 0,4202 & 0,0972 & 0,8717 & 0,7988 & 0,0034 \\
\hline
\end{tabular}

Fonte: Elaboração do autor com base nos microdados do PENSE, 2012.

Nota: ${ }^{* *},{ }^{* *},{ }^{*}$ denotam significância ao nível de $1 \%$, 5\% e $10 \%$, respectivamente. Cada observação foi ponderada pelo número de alunos na escola. Valores entre parênteses são os erros padrão estimados através do estimador robusto de Huber-White, que considera a matriz de covariância residual agrupada por escola. 
Tabela 6 - Estimativas por MQ2E para o consumo de álcool

\begin{tabular}{|c|c|c|c|c|c|c|}
\hline & \multicolumn{3}{|c|}{ Escola Pública } & \multicolumn{3}{|c|}{ Escola Privada } \\
\hline & 14 & $<14$ & $>14$ & 14 & $<14$ & $>14$ \\
\hline Efeito interação (MQO) & $\begin{array}{c}0,400^{* * *} \\
(0,027)\end{array}$ & $\begin{array}{c}0,416^{* * *} \\
(0,045)\end{array}$ & $\begin{array}{c}0,390^{* * *} \\
(0,028)\end{array}$ & $\begin{array}{c}0,416^{\star * *} \\
(0,053)\end{array}$ & $\begin{array}{c}0,455^{\star * *} \\
(0,061)\end{array}$ & $\begin{array}{c}0,201^{* * *} \\
(0,072)\end{array}$ \\
\hline Efeito interação (MQ2E) & $\begin{array}{c}0,457^{\star \star \star} \\
(0,078)\end{array}$ & $\begin{array}{c}0,192 \\
(0,165)\end{array}$ & $\begin{array}{c}0,372^{* \star *} \\
(0,086)\end{array}$ & $\begin{array}{c}0,455^{\star * *} \\
(0,132)\end{array}$ & $\begin{array}{c}0,607^{\star \star *} \\
(0,162)\end{array}$ & $\begin{array}{c}0,230 \\
(0,205)\end{array}$ \\
\hline Meninos & $\begin{array}{c}-0,073^{* * *} \\
(0,006)\end{array}$ & $\begin{array}{c}-0,065^{\star * *} \\
(0,009)\end{array}$ & $\begin{array}{l}-0,007 \\
(0,006)\end{array}$ & $\begin{array}{c}-0,03^{\star * \star} \\
(0,009)\end{array}$ & $\begin{array}{c}-0,038^{* * *} \\
(0,014)\end{array}$ & $\begin{array}{l}-0,022 \\
(0,015)\end{array}$ \\
\hline Não brancos & $\begin{array}{l}-0,005 \\
(0,006)\end{array}$ & $\begin{array}{l}-0,002 \\
(0,009)\end{array}$ & $\begin{array}{l}0,011^{*} \\
(0,007)\end{array}$ & $\begin{array}{c}0,009 \\
(0,010)\end{array}$ & $\begin{array}{c}0,018 \\
(0,016)\end{array}$ & $\begin{array}{l}-0,007 \\
(0,015)\end{array}$ \\
\hline Idade & & $\begin{array}{c}0,076^{* * *} \\
(0,024)\end{array}$ & $\begin{array}{c}0,026^{* \star *} \\
(0,004)\end{array}$ & & $\begin{array}{c}0,093^{* * *} \\
(0,034)\end{array}$ & $\begin{array}{c}0,031^{* * *} \\
(0,011)\end{array}$ \\
\hline Trabalha & $\begin{array}{c}0,095^{\star \star \star} \\
(0,009)\end{array}$ & $\begin{array}{c}0,103^{\star \star \star} \\
(0,014)\end{array}$ & $\begin{array}{c}0,068^{* * *} \\
(0,007)\end{array}$ & $\begin{array}{c}0,067^{\star * *} \\
(0,016)\end{array}$ & $\begin{array}{c}0,158^{\star \star *} \\
(0,023)\end{array}$ & $\begin{array}{c}0,077^{\star \star \star} \\
(0,018)\end{array}$ \\
\hline Índice do nível de vida & $\begin{array}{c}0,020^{\star \star \star} \\
(0,002)\end{array}$ & $\begin{array}{c}0,023^{\star \star \star} \\
(0,004)\end{array}$ & $\begin{array}{c}0,023^{* \star *} \\
(0,002)\end{array}$ & $\begin{array}{c}0,025^{\star \star *} \\
(0,005)\end{array}$ & $\begin{array}{c}0,025^{\star \star \star} \\
(0,008)\end{array}$ & $\begin{array}{c}0,031^{\star \star \star} \\
(0,009)\end{array}$ \\
\hline Um dos pais com faculdade & $\begin{array}{c}0,010 \\
(0,010)\end{array}$ & $\begin{array}{c}0,037^{\star \star \star} \\
(0,012)\end{array}$ & $\begin{array}{c}0,017 \\
(0,013)\end{array}$ & $\begin{array}{c}0,013 \\
(0,009)\end{array}$ & $\begin{array}{l}0,031^{\star *} \\
(0,013)\end{array}$ & $\begin{array}{l}0,030^{*} \\
(0,016)\end{array}$ \\
\hline Família uniparental & $\begin{array}{c}0,065^{\star * *} \\
(0,005)\end{array}$ & $\begin{array}{c}0,071^{* * *} \\
(0,009)\end{array}$ & $\begin{array}{c}0,061^{* * *} \\
(0,006)\end{array}$ & $\begin{array}{c}0,054^{* * *} \\
(0,010)\end{array}$ & $\begin{array}{c}0,073^{* * *} \\
(0,014)\end{array}$ & $\begin{array}{c}0,045^{\star * *} \\
(0,014)\end{array}$ \\
\hline Pais não ajudam no dever & $\begin{array}{c}0,127^{\star \star *} \\
(0,006)\end{array}$ & $\begin{array}{c}0,158^{\star \star *} \\
(0,009)\end{array}$ & $\begin{array}{c}0,107^{* * *} \\
(0,006)\end{array}$ & $\begin{array}{c}0,110^{* * *} \\
(0,010)\end{array}$ & $\begin{array}{c}0,111^{\star * *} \\
(0,014)\end{array}$ & $\begin{array}{c}0,067^{\star \star \star} \\
(0,013)\end{array}$ \\
\hline Não almoça com pais & $\begin{array}{c}0,058^{\star * \star} \\
(0,006)\end{array}$ & $\begin{array}{c}0,052^{\star \star \star} \\
(0,011)\end{array}$ & $\begin{array}{l}0,061^{\star * *} \\
(0,006)\end{array}$ & $\begin{array}{c}0,035^{* * *} \\
(0,011)\end{array}$ & $\begin{array}{c}0,049^{\star * *} \\
(0,016)\end{array}$ & $\begin{array}{l}0,064^{\star \star \star} \\
(0,015)\end{array}$ \\
\hline Um dos pais fuma & $\begin{array}{c}0,092^{* * *} \\
(0,006)\end{array}$ & $\begin{array}{c}0,100^{\star * \star} \\
(0,010)\end{array}$ & $\begin{array}{c}0,092^{\star * *} \\
(0,006)\end{array}$ & $\begin{array}{c}0,073^{\star * *} \\
(0,011)\end{array}$ & $\begin{array}{c}0,086^{* * *} \\
(0,017)\end{array}$ & $\begin{array}{l}0,071^{* * *} \\
(0,016)\end{array}$ \\
\hline Pais deixam fumar & $\begin{array}{l}-0,020 \\
(0,013)\end{array}$ & $\begin{array}{l}-0,020 \\
(0,027)\end{array}$ & $\begin{array}{c}-0,04^{\star \star \star} \\
(0,012)\end{array}$ & $\begin{array}{c}0,021 \\
(0,024)\end{array}$ & $\begin{array}{l}-0,006 \\
(0,049)\end{array}$ & $\begin{array}{l}-0,031 \\
(0,035)\end{array}$ \\
\hline Pais deixam beber & $\begin{array}{c}0,063^{\star * *} \\
(0,014)\end{array}$ & $\begin{array}{l}0,053^{\star *} \\
(0,025)\end{array}$ & $\begin{array}{c}0,060^{* \star *} \\
(0,010)\end{array}$ & $\begin{array}{c}0,068^{* * *} \\
(0,024)\end{array}$ & $\begin{array}{c}0,029 \\
(0,051)\end{array}$ & $\begin{array}{c}0,036 \\
(0,025)\end{array}$ \\
\hline Capital & $\begin{array}{c}0,000 \\
(0,006)\end{array}$ & $\begin{array}{c}0,006 \\
(0,012)\end{array}$ & $\begin{array}{l}0,012^{\star} \\
(0,007)\end{array}$ & $\begin{array}{l}-0,006 \\
(0,010)\end{array}$ & $\begin{array}{c}-0,030^{* *} \\
(0,012)\end{array}$ & $\begin{array}{c}0,053^{\star \star \star} \\
(0,019)\end{array}$ \\
\hline Base & & & & & & \\
\hline $\mathrm{N}$ & $\begin{array}{c}-0,022^{* * *} \\
(0,008)\end{array}$ & $\begin{array}{l}-0,015 \\
(0,013)\end{array}$ & $\begin{array}{c}-0,03^{* * *} \\
(0,008)\end{array}$ & $\begin{array}{l}-0,023^{\star} \\
(0,013)\end{array}$ & $\begin{array}{l}-0,015 \\
(0,018)\end{array}$ & $\begin{array}{l}-0,041 \\
(0,028)\end{array}$ \\
\hline SE & $\begin{array}{c}0,037^{\star * *} \\
(0,010)\end{array}$ & $\begin{array}{c}0,070^{* \star *} \\
(0,024)\end{array}$ & $\begin{array}{l}-0,011 \\
(0,010)\end{array}$ & $\begin{array}{c}0,011 \\
(0,012)\end{array}$ & $\begin{array}{l}-0,010 \\
(0,019)\end{array}$ & $\begin{array}{c}0,028 \\
(0,021)\end{array}$ \\
\hline S & $\begin{array}{c}0,081^{* *} \\
(0,015)\end{array}$ & $\begin{array}{c}0,162^{* *} \\
(0,035)\end{array}$ & $\begin{array}{c}0,020 \\
(0,016)\end{array}$ & $\begin{array}{c}0,064^{\star * \star} \\
(0,018)\end{array}$ & $\begin{array}{l}0,036^{*} \\
(0,021)\end{array}$ & $\begin{array}{l}0,067^{* *} \\
(0,032)\end{array}$ \\
\hline $\mathrm{CO}$ & $\begin{array}{c}0,037^{\star \star *} \\
(0,010)\end{array}$ & $\begin{array}{l}0,101^{* \star *} \\
(0,024)\end{array}$ & $\begin{array}{c}0,002 \\
(0,011)\end{array}$ & $\begin{array}{l}0,041^{\star *} \\
(0,018)\end{array}$ & $\begin{array}{l}-0,003 \\
(0,018)\end{array}$ & $\begin{array}{c}0,029 \\
(0,024)\end{array}$ \\
\hline Constante & $\begin{array}{c}0,228^{* * *} \\
(0,046)\end{array}$ & $\begin{array}{c}-0,692^{* *} \\
(0,317)\end{array}$ & $\begin{array}{l}-0,075 \\
(0,078)\end{array}$ & $\begin{array}{c}0,260^{* * *} \\
(0,088)\end{array}$ & $\begin{array}{c}-1,097^{\star *} \\
(0,448)\end{array}$ & $\begin{array}{c}0,003 \\
(0,212)\end{array}$ \\
\hline Observações & 37.842 & 15.431 & 29.986 & 12.334 & 6.683 & 3.274 \\
\hline Escolas & 2.216 & 2.068 & 2.218 & 606 & 605 & 571 \\
\hline $\mathrm{R}^{2}$ & 0,0861 & 0,1042 & 0,0745 & 0,0524 & 0,0580 & 0,0688 \\
\hline $\mathrm{F}$ & 23,68 & 16,16 & 19,44 & 7,81 & 6,94 & 7,86 \\
\hline$\chi^{2}$ & 35,5926 & 10,4488 & 13,7849 & 5,42162 & 4,59772 & 7,28075 \\
\hline Valor $p$ & 0,0000 & 0,1070 & 0,0321 & 0,4910 & 0,5963 & 0,2957 \\
\hline
\end{tabular}

Fonte: Elaboração do autor com base nos microdados do PENSE, 2012.

Nota: ***, ${ }^{* *},{ }^{*}$ denotam significância ao nível de $1 \%, 5 \%$ e $10 \%$, respectivamente. Cada observação foi ponderada pelo número de alunos na escola. Valores entre parênteses são os erros padrão estimados através do estimador robusto de Huber-White, que considera a matriz de covariância residual agrupada por escola. 
Tabela 7 - Estimativas por MQ2E para o consumo de cigarro

\begin{tabular}{|c|c|c|c|c|c|c|}
\hline & \multicolumn{3}{|c|}{ Escola Pública } & \multicolumn{3}{|c|}{ Escola Privada } \\
\hline & 14 & $<14$ & $>14$ & 14 & $<14$ & $>14$ \\
\hline Efeito interação (MQO) & $\begin{array}{c}0,471^{* * \star} \\
(0,025)\end{array}$ & $\begin{array}{c}0,384^{\star \star \star} \\
(0,038)\end{array}$ & $\begin{array}{c}0,518^{\star \star *} \\
(0,030)\end{array}$ & $\begin{array}{c}0,400^{\star \star *} \\
(0,054)\end{array}$ & $\begin{array}{c}0,248^{\star \star \star} \\
(0,049) \\
\end{array}$ & $\begin{array}{c}0,484^{* \star *} \\
(0,108)\end{array}$ \\
\hline Efeito interação (MQ2E) & $\begin{array}{c}0,501^{* * *} \\
(0,051)\end{array}$ & $\begin{array}{c}0,396^{\star \star \star} \\
(0,081)\end{array}$ & $\begin{array}{c}0,444^{* * *} \\
(0,072)\end{array}$ & $\begin{array}{c}0,603^{* * *} \\
(0,091)\end{array}$ & $\begin{array}{l}0,256^{*} \\
(0,134)\end{array}$ & $\begin{array}{l}0,565^{\star *} \\
(0,239)\end{array}$ \\
\hline Meninos & $\begin{array}{l}-0,002 \\
(0,005)\end{array}$ & $\begin{array}{l}-0,000 \\
(0,007)\end{array}$ & $\begin{array}{c}0,029^{* \star *} \\
(0,006)\end{array}$ & $\begin{array}{c}0,008 \\
(0,007)\end{array}$ & $\begin{array}{l}0,019^{*} \\
(0,010)\end{array}$ & $\begin{array}{c}0,052^{\star * *} \\
(0,019)\end{array}$ \\
\hline Não brancos & $\begin{array}{c}0,020^{\star * \star} \\
(0,005)\end{array}$ & $\begin{array}{c}0,009 \\
(0,007)\end{array}$ & $\begin{array}{c}0,010 \\
(0,007)\end{array}$ & $\begin{array}{l}0,019^{\star *} \\
(0,008)\end{array}$ & $\begin{array}{c}0,011 \\
(0,008)\end{array}$ & $\begin{array}{c}0,011 \\
(0,019)\end{array}$ \\
\hline Idade & & $\begin{array}{c}0,043^{\star * *} \\
(0,012)\end{array}$ & $\begin{array}{c}0,037^{\star \star *} \\
(0,005)\end{array}$ & & $\begin{array}{c}0,049^{* \star *} \\
(0,011)\end{array}$ & $\begin{array}{c}0,054^{* * *} \\
(0,016)\end{array}$ \\
\hline Trabalha & $\begin{array}{c}0,100^{\star \star \star} \\
(0,008)\end{array}$ & $\begin{array}{c}0,094^{* * *} \\
(0,014)\end{array}$ & $\begin{array}{c}0,067^{\star \star *} \\
(0,008)\end{array}$ & $\begin{array}{c}0,084^{\star \star *} \\
(0,019)\end{array}$ & $\begin{array}{c}0,082^{* *} \\
(0,025)\end{array}$ & $\begin{array}{c}0,084^{\star * *} \\
(0,029)\end{array}$ \\
\hline Índice do nível de vida & $\begin{array}{l}-0,002 \\
(0,002)\end{array}$ & $\begin{array}{l}-0,005^{*} \\
(0,002)\end{array}$ & $\begin{array}{c}0,003 \\
(0,002)\end{array}$ & $\begin{array}{c}0,003 \\
(0,005)\end{array}$ & $\begin{array}{l}-0,003 \\
(0,006)\end{array}$ & $\begin{array}{c}0,008 \\
(0,010)\end{array}$ \\
\hline Um dos pais com faculdade & $\begin{array}{c}0,006 \\
(0,007)\end{array}$ & $\begin{array}{c}0,010 \\
(0,010)\end{array}$ & $\begin{array}{c}0,011 \\
(0,012)\end{array}$ & $\begin{array}{c}0,003 \\
(0,007)\end{array}$ & $\begin{array}{l}-0,007 \\
(0,008)\end{array}$ & 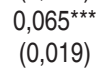 \\
\hline Família uniparental & $\begin{array}{c}0,052^{* * *} \\
(0,005)\end{array}$ & $\begin{array}{c}0,041^{* * *} \\
(0,007)\end{array}$ & 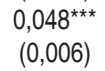 & $\begin{array}{c}0,037^{\star \star *} \\
(0,007)\end{array}$ & $\begin{array}{l}0,019^{* *} \\
(0,009)\end{array}$ & $\begin{array}{l}0,042^{* *} \\
(0,018)\end{array}$ \\
\hline Pais não ajudam no dever & $\begin{array}{c}0,076^{\star \star \star} \\
(0,005)\end{array}$ & $\begin{array}{c}0,071^{\star \star \star} \\
(0,007)\end{array}$ & $\begin{array}{c}0,100^{* \star *} \\
(0,006)\end{array}$ & $\begin{array}{c}0,035^{\star \star *} \\
(0,007)\end{array}$ & $\begin{array}{c}0,040^{\star \star \star} \\
(0,008)\end{array}$ & $\begin{array}{c}0,098^{* \star *} \\
(0,019)\end{array}$ \\
\hline Não almoça com pais & $\begin{array}{c}0,053^{* * *} \\
(0,005)\end{array}$ & $\begin{array}{c}0,048^{* * *} \\
(0,009)\end{array}$ & $\begin{array}{c}0,063^{\star \star *} \\
(0,007)\end{array}$ & $\begin{array}{c}0,048^{\star * *} \\
(0,010)\end{array}$ & $\begin{array}{c}0,037^{* * *} \\
(0,013)\end{array}$ & $\begin{array}{c}0,104^{* \star *} \\
(0,023)\end{array}$ \\
\hline Um dos pais fuma & $\begin{array}{c}0,082^{* \star *} \\
(0,005)\end{array}$ & $\begin{array}{c}0,084^{\star \star \star} \\
(0,009)\end{array}$ & $\begin{array}{c}0,092^{* * *} \\
(0,007)\end{array}$ & $\begin{array}{c}0,065^{\star \star *} \\
(0,012)\end{array}$ & $\begin{array}{c}0,062^{\star \star *} \\
(0,013)\end{array}$ & $\begin{array}{c}0,069^{* \star *} \\
(0,025)\end{array}$ \\
\hline Pais deixam fumar & $\begin{array}{c}0,024 \\
(0,015)\end{array}$ & $\begin{array}{l}-0,007 \\
(0,023)\end{array}$ & $\begin{array}{c}0,009 \\
(0,014)\end{array}$ & $\begin{array}{c}0,108^{\star \star *} \\
(0,034)\end{array}$ & $\begin{array}{c}0,011 \\
(0,045)\end{array}$ & $\begin{array}{c}0,147^{\star \star *} \\
(0,052)\end{array}$ \\
\hline Pais deixam beber & $\begin{array}{c}0,143^{* \star *} \\
(0,019)\end{array}$ & $\begin{array}{c}0,140^{\star \star \star} \\
(0,029)\end{array}$ & $\begin{array}{c}0,140^{* \star *} \\
(0,016)\end{array}$ & $\begin{array}{c}0,079^{* \star *} \\
(0,030)\end{array}$ & $\begin{array}{l}0,123^{\star *} \\
(0,051)\end{array}$ & $\begin{array}{c}0,142^{* \star *} \\
(0,043)\end{array}$ \\
\hline Capital & $\begin{array}{l}0,009^{*} \\
(0,005)\end{array}$ & $\begin{array}{l}0,019^{\star *} \\
(0,008)\end{array}$ & $\begin{array}{c}0,049^{\star \star *} \\
(0,008)\end{array}$ & $\begin{array}{c}-0,02^{\star \star *} \\
(0,006)\end{array}$ & $\begin{array}{l}-0,011 \\
(0,008)\end{array}$ & $\begin{array}{c}0,080^{\star * *} \\
(0,024)\end{array}$ \\
\hline Base (NE) & & & & & & \\
\hline $\mathrm{N}$ & $\begin{array}{c}0,008 \\
(0,006)\end{array}$ & $\begin{array}{c}0,009 \\
(0,009)\end{array}$ & $\begin{array}{l}0,017^{* *} \\
(0,008)\end{array}$ & $\begin{array}{l}-0,013 \\
(0,008)\end{array}$ & $\begin{array}{c}0,029^{\star \star *} \\
(0,010)\end{array}$ & $\begin{array}{l}0,059^{* *} \\
(0,027)\end{array}$ \\
\hline SE & $\begin{array}{c}0,010 \\
(0,006)\end{array}$ & $\begin{array}{l}0,025^{\star *} \\
(0,011)\end{array}$ & $\begin{array}{c}0,028^{\star \star *} \\
(0,010)\end{array}$ & $\begin{array}{c}-0,012^{*} \\
(0,007)\end{array}$ & $\begin{array}{l}0,023^{*} \\
(0,012)\end{array}$ & $\begin{array}{l}0,058^{\star *} \\
(0,026)\end{array}$ \\
\hline S & $\begin{array}{c}0,084^{\star \star \star} \\
(0,011)\end{array}$ & $\begin{array}{c}0,055^{\star \star \star} \\
(0,015)\end{array}$ & $\begin{array}{c}0,127^{\star \star \star} \\
(0,016)\end{array}$ & $\begin{array}{l}0,032^{\star *} \\
(0,014)\end{array}$ & $\begin{array}{c}0,052^{\star \star *} \\
(0,014)\end{array}$ & $\begin{array}{c}0,209^{* \star *} \\
(0,061)\end{array}$ \\
\hline $\mathrm{CO}$ & $\begin{array}{c}0,038^{\star \star \star} \\
(0,008)\end{array}$ & $\begin{array}{c}0,043^{\star \star \star} \\
(0,014)\end{array}$ & $\begin{array}{c}0,064^{* \star *} \\
(0,011)\end{array}$ & $\begin{array}{l}0,021^{\star *} \\
(0,009)\end{array}$ & $\begin{array}{c}0,022 \\
(0,016)\end{array}$ & $\begin{array}{l}0,069^{* *} \\
(0,031)\end{array}$ \\
\hline Constante & $\begin{array}{c}-0,068^{\star \star \star} \\
(0,010)\end{array}$ & $\begin{array}{c}-0,629^{\star \star *} \\
(0,155)\end{array}$ & $\begin{array}{c}-0,59^{\star \star \star} \\
(0,071)\end{array}$ & $\begin{array}{l}-0,021 \\
(0,015)\end{array}$ & $\begin{array}{c}-0,644^{\star * *} \\
(0,146)\end{array}$ & $\begin{array}{c}-0,931^{\star \star \star} \\
(0,239)\end{array}$ \\
\hline Obsen & 37.843 & 15.430 & 29.984 & 12.334 & 6.683 & 3.274 \\
\hline $\begin{array}{l}\text { Escolas } \\
\mathrm{R}^{2}\end{array}$ & $\begin{array}{l}2.216 \\
0,0791\end{array}$ & $\begin{array}{c}2.068 \\
0,0744\end{array}$ & $\begin{array}{c}2.218 \\
0,0902\end{array}$ & $\begin{array}{c}606 \\
0,0462\end{array}$ & $\begin{array}{c}605 \\
0,0422\end{array}$ & $\begin{array}{c}571 \\
0,1042\end{array}$ \\
\hline $\mathrm{F}$ & 41,95 & 35,72 & 35,75 & 15,87 & 12,83 & 11,90 \\
\hline$\chi^{2}$ & 4,71396 & 4,45141 & 18,9571 & 2,47903 & 2,57565 & 14,8124 \\
\hline Valor $p$ & 0,5810 & 0,6158 & 0,0042 & 0,8708 & 0,8599 & 0,0218 \\
\hline
\end{tabular}

Fonte: Elaboração do autor com base nos microdados do PENSE, 2012.

Nota: ${ }^{* * *},{ }^{* *},{ }^{*}$ denotam significância ao nível de $1 \%, 5 \%$ e $10 \%$, respectivamente. Cada observação foi ponderada pelo número de alunos na escola. Valores entre parênteses são os erros padrão estimados através do estimador robusto de Huber-White, que considera a matriz de covariância residual agrupada por escola. 
Com o intuito de comparar os resultados, a terceira linha das Tabelas 5 , 6 e 7 reporta o efeito interação estimado através do método de MQO. ${ }^{5} \mathrm{Na}$ maioria dos casos, o efeito interação estimado por MQ2E é maior que o estimado por MQO. As exceções foram o consumo de drogas para jovens com mais de 14 anos em escolas privadas, o consumo de álcool e cigarros dos jovens com mais de 14 anos em escolas públicas e o consumo de álcool dos jovens com menos de 14 anos nas escolas públicas. Porém, conforme apontado no parágrafo anterior, os instrumentos utilizados não foram válidos para estas categorias. De maneira geral, os resultados indicam a existência de problemas de simultaneidade que, de alguma forma, podem subestimar as estimativas do efeito interação obtidas pelo método de MQO.

As estimativas do efeito de interação social são positivas e indicaram que, por exemplo, se um jovem com 14 anos em uma escola pública onde nenhum colega usa drogas for transferido para uma escola onde a metade dos alunos usam drogas, a probabilidade de este jovem experimentar drogas seria acrescida em 21,6 pontos percentuais $(0,433$ $\times 0,5=0,216)$. Os resultados para os jovens em escolas privadas são semelhantes.

Outra indicação interessante destes resultados é que os efeitos de interação social parecem ser maiores em comparação à influência das características das famílias nas decisões de consumo de drogas, álcool e cigarros dos jovens. Por exemplo, transferir um jovem com 14 anos de uma escola pública onde $80 \%(0,501 \times 0,8=0,40)$ dos alunos fumam para uma escola onde esta taxa é de $50 \%(0,501 \times$ $0,5=0,25)$, compensaria completamente o maior risco de o jovem fumar associado ao fato de um dos pais fumar $(0,082)$.

Embora o efeito de interação social seja o maior coeficiente estimado, as variáveis de controle também apresentaram resultados significativos na determinação das decisões de consumo de drogas, álcool e cigarros. Os coeficientes significativos das variáveis de características pessoais indicaram que os meninos com idade entre 15 e 17 anos são mais suscetíveis a experimentar drogas e cigarros se comparado às meninas. Porém, meninos com idade entre 12 e 14 anos são menos suscetíveis ao consumo de álcool. Jovens não brancos com idade en-

5 Este resultado foi obtido através da estimação do modelo incluindo as variáveis de controle descritas na Tabela 2, que são as mesmas do modelo de MQ2E. Os resultados da estimação do modelo completo por MQO, com os demais coeficientes estimados, podem ser obtidos diretamente com os autores. 
tre 12 e 14 em escolas privadas são mais suscetíveis ao consumo de drogas. Quanto maior a idade do jovem, maior a possibilidade de que ele tenha experimentado drogas, álcool ou cigarros.

O fato de o jovem trabalhar aumenta, aproximadamente, entre 3,6 e 5,9 pontos percentuais (p.p.) a possibilidade de ter consumido drogas, dependendo da categoria de informações analisadas, e entre 6,7 e 15,8 p.p. de ter consumido de álcool ou cigarros, o que pode ser devido à autonomia das decisões de consumo proporcionada pela independência financeira do trabalho remunerado.

Os coeficientes significativos das variáveis do jovem que pertence a uma família uniparental, que os pais não ajudam no dever e que não almoça com pais foram todos positivos. Estas variáveis foram incluídas no modelo como medidas de estrutura da família e os resultados observados podem ser um indicativo de que a ausência dos pais, seja ela física ou devido à falta de envolvimento e dedicação nas atividades dos filhos, está relacionada com as decisões de consumo ilícito dos jovens. Já em relação aos filhos de pais que fumam tem maior probabilidade de ter experimentado drogas, álcool ou cigarros. No caso do consumo de cigarros, o aumento é entre 8,2 e 9,2 p.p. para os alunos de escolas públicas e entre 6,2 e 6,9 p.p. para os alunos de escolas privadas. Já no caso de os pais serem permissivos em relação ao consumo de cigarro pelos filhos, é interessante observar que poucos coeficientes foram significativos. Alguns valores positivos são observados nas equações de consumo de drogas e cigarros dos alunos de escolas privadas. Para a categoria de consumo de álcool dos alunos de escolas públicas com mais de 14 anos, o coeficiente estimado apresentou valor negativo. Talvez isso ocorra porque, no caso do cigarro, cujas campanhas publicitárias de incentivo ao consumo são proibidas e os malefícios são amplamente divulgados, a conduta e o exemplo dos pais tenham uma importância maior para os filhos do que o controle ao consumo desta substância. Por outro lado, o fato de os pais permitirem o consumo álcool dos filhos aumenta as chances de o jovem experimentar as três substâncias analisadas. Os coeficientes significativos indicam que este aumento é, aproximadamente, entre 5 e 14 p.p., dependendo da categoria de informações analisadas. 
Muitos coeficientes das variáveis do índice do nível de vida e de um dos pais ter faculdade não apresentaram significância estatística. Porém, aqueles que são significativos estão positivamente relacionadas ao fato de o jovem ter experimentado substâncias ilícitas, destacando-se o caso da relação entre índice do nível de vida e o consumo de álcool, em que todos os coeficientes foram significativos. Embora os valores sejam pequenos, entre 0,2 e 6,5 p.p, este fato pode ser uma evidência de que as decisões de consumo ilícito dos jovens estão mais relacionadas com o exemplo e o envolvimento dos pais nas atividades e no cotidiano das crianças do que com o nível de educação formal dos pais e a renda da família. Neste mesmo sentido, Case e Katz (1991) observaram uma relação positiva entre os anos de escolaridade dos pais e o consumo ilegal de drogas dos jovens e Gaviria e Raphael (2001) observaram uma relação positiva entre o status socioeconômico da família, composto pelo nível educacional, ocupação e renda dos pais, e o consumo de drogas e álcool, ambos os estudos utilizaram informações de jovens norte-americanos.

Dos coeficientes significativos das variáveis de localização, observase que os jovens de escolas públicas que residem em uma capital têm maior probabilidade de ter experimentado substâncias ilícitas. Para as escolas privadas, no caso do consumo de drogas, nenhum coeficiente foi significativo, e algumas categorias de consumo de álcool e cigarros apresentaram coeficientes positivos e outras negativos. Comparados à região Nordeste, de maneira geral, os jovens que residem nas demais regióes tem maiores chances de experimentar as substâncias analisadas, com exceção da região Norte, onde alguns coeficientes significativos apresentaram valor negativo.

\subsection{Escolas em áreas de risco e a escolha dos pais}

Um problema bastante comum nos estudos, que buscam analisar a influência dos pares no comportamento do jovem, é que os pais podem controlar a interação social dos seus filhos ao definirem a escola ou a vizinhança. Dessa forma, a escolha dos pares por parte do jovem torna-se restrita aos indivíduos que compóem a escola selecionada pelos pais. Este fato pode trazer problemas de endogeneidade ao modelo se os pais mais preocupados com a educação e com a influência com a qual seus filhos estão expostos dispenderem mais 
recursos financeiros e de tempo para escolher as melhores escolas e vizinhanças para os seus filhos. Se esta conscientização dos pais for não observável e correlacionada com a média do comportamento do grupo, as estimativas do efeito interação serão superestimadas.

Se considerarmos que as variáveis utilizadas para controlar o envolvimento dos pais com seus filhos possam ser, de certa forma, uma medida da conscientização dos pais, talvez o problema de endogeneidade não seja tão grave neste estudo. Mesmo assim, para tentar mensurar uma possível existência de viés, pressupomos que os pais com condições financeiras e preocupados com o meio que seus filhos estão expostos, poderiam escolher escolas localizadas em áreas com maior segurança e, neste caso, a correlação entre a conscientização não observada dos pais e o efeito médio de interação do grupo seria maior para os jovens nestas escolas do que nas escolas localizadas em um ambiente hostil. Sendo assim, consideramos uma amostra formada por alunos de escolas privadas com mensalidade maior que $\mathrm{R} \$ 662,00$, que caracterizaria famílias com condições financeiras de selecionar a escola, e subdividimos esta amostra em dois grupos, um de escolas situadas em área de risco em termos de violência ${ }^{6}$ (roubos, furtos, assaltos, troca de tiros, homicídios, etc.) e outro de escolas que não se localizam em áreas de risco.

O resumo dos resultados das estimativas do efeito de interação social destes dois grupos está representado na Tabela 8. ${ }^{7}$ Para observar se as estimativas de ambos os grupos são estatisticamente equivalentes, o modelo considerando as observações das escolas não localizadas em áreas de risco foi estimado novamente, incluindo como restrição os coeficientes do efeito interação dos jovens nas escolas em áreas de risco. As duas últimas colunas da tabela apresentam os resultados dos testes de restrição. A hipótese nula de que os coeficientes são estatisticamente iguais foi rejeitada apenas no caso do consumo de drogas. Para o consumo de álcool e cigarros, os resultados não indicaram evidência de viés nas estimativas do efeito interação devido à escolha endógena das escolas pelas famílias, uma vez que os coeficientes são estatisticamente equivalentes para os jovens nos grupos de comparação.

6 Esta informação foi obtida no questionário do diretor da escola e refere-se ao risco, em termos de violência, na localidade onde a escola está situada nos últimos 12 meses.

7 As estimativas formam realizadas utilizando as variáveis de controle apresentadas na Tabela 2. 
Desta forma, os resultados do exercício para a identificação de endogeneidade na escolha dos grupos produziram resultados distintos, dependendo da categoria de consumo analisada. Uma possível explicação, segundo Gaviria e Raphael (2001), é que mesmo que a escolha da escola ou da vizinhança seja endógena, isso não garante a total "qualidade" dos pares porque é praticamente impossível para os pais controlar a interação social dos seus filhos em diferentes dimensões (consumo de drogas, álcool, cigarros, proficiência escolar, similaridade religiosa, etc.).

Tabela 8 - Comparação do efeito interação no comportamento dos jovens em escolas privadas localizadas em áreas consideradas de risco ou não

\begin{tabular}{lccc}
\hline & Droga & Álcool & Cigarro \\
\hline Área de risco & 0,0709 & 0,3522 & 0,2289 \\
Estatística $t$ & 0,22 & 2,81 & 1,07 \\
Observações & 1.519 & 1.519 & 1.519 \\
Não é área de risco & 0,4207 & 0,3461 & 0,2830 \\
Estatística $t$ & 3,02 & 2,72 & 2,20 \\
Observações & 3.266 & 3.266 & 3.266 \\
$F$ & 6,30 & 0,00 & 0,18 \\
Valor $p$ & 0,0121 & 0,9615 & 0,6748 \\
\hline
\end{tabular}

Nota: erros-padrão obtidos através do estimador robusto de Huber-White.

Os autores realizaram um exercício semelhante, porém utilizaram as diferenças na mobilidade residencial das famílias nos Estados Unidos para compor os grupos de comparação. Sob a hipótese de que a correlação entre a conscientização não observada dos pais e o efeito médio de interação do grupo é maior para as famílias que se mudaram recentemente, a estimativa do efeito de interação social neste grupo deveria ser maior em comparação as famílias que permaneceram na mesma vizinhança. Das cinco medidas analisadas, uso de drogas, álcool, cigarros, frequência na igreja e evasão escolar, apenas para uso de drogas foi observada uma estimativa estatisticamente distinta para o efeito interação, coincidindo com os resultados do presente estudo. 


\section{Conclusões}

Este estudo buscou analisar a influência do efeito das interações sociais no ambiente da escola, pública e privada, sobre as decisões de consumo dos jovens, no que se refere ao uso de drogas ilícitas, álcool ou cigarro através dos dados do PENSE - 2012. Foram realizadas estimativas de um modelo de comportamento individual através do método de $M Q 2 E$, utilizando como instrumentos para o efeito interação sete variáveis de características médias das famílias dos colegas, sob a hipótese de que estas características influenciam o comportamento do colega que pertence à família, porém supõe-se ausência de relação direta entre o comportamento individual e a média de características das famílias dos colegas.

Os resultados do estudo indicaram fortes evidências do efeito das interações sociais no fato de o jovem ter experimentado drogas, álcool ou cigarros. Estes efeitos mostraram-se maiores em comparação à influência das características das famílias nas decisões de consumo destas substâncias. Por exemplo, transferir um jovem de uma escola pública onde $80 \%$ dos alunos fumam para uma escola onde esta taxa é de 50\%, compensaria completamente o maior risco de o jovem fumar associado ao fato de um dos pais fumar.

Estes resultados são uma evidência de que a escola, através das interações que se estabelecem entre os alunos neste ambiente, tem um papel fundamental sobre as decisões dos jovens. Dessa forma, as políticas educacionais de prevenção ao consumo de substâncias ilícitas que conseguem evitar que um jovem experimente uma droga evitam também o desencadeamento do multiplicador comportamental, em que um indivíduo influencia as decisões dos demais através das interações. Além disso, as políticas de controle e acompanhamento de um aluno usuário, direcionadas para inibir o consumo e reabilitar o jovem, podem evitar a influência deste sobre os demais alunos e atuar como uma forma de prevenção ao consumo de drogas dos colegas que convivem com um jovem usuário na escola.

Além disso, os resultados do estudo indicaram que o envolvimento dos pais com as atividades dos filhos pode ser mais importante para inibir o consumo de drogas, álcool e cigarros do que a escolaridade dos pais e o nível de vida da família. Embora os percentuais sejam pequenos, este fato pode ser uma evidência de que as decisões de 
consumo ilícito dos jovens estão mais relacionadas com o exemplo e o envolvimento dos pais nas atividades e no cotidiano das crianças do que com o nível de educação formal dos pais e a renda da família.

\section{Referências}

ANGRIST, J. D. The perils of peer effects. Labour Economics, Vol. 30, p. 98-108, 2014.

ANGRIST, J. D.; LANG, K. Does School Integration Generate Peer Effects? Evidence from Boston's Metco Program. The American Economic Review, Vol. 94, No. 5 (Dec., 2004), pp. 1613-1634, 2004.

BANERJEE, A.V. A simple model of herd behavior. The Quarterly Journal of Economics, Oxford, v. 107, p.797-817, 1992.

BECKER, G. Accounting for Tastes. Cambridge, MA: Harvard University Press, 1996.

BOBONIS, G. J.; FINAN, F. Neighborhood peer effects in secondary school enrollment decisions. The Review of Economics and Statistics, November 2009, 91(4): 695-716, 2009.

BROCK, W. A.; DURLAUF, S. N. Identification of binary choice models with social interactions. Journal of Econometrics, 140, 52-75, 2007.

CASE, A.; KATZ, L. The company you keep: the effects of family and neighborhood on disadvantaged youths. Cambridge: NBER, p. 1-41 (NBER working paper, 3705), 1991.

COLEMAN, J. S. Foundations of Social Theory. Cambridge, MA: Harvard University Press, 1990.

DUFLO, E.; DUPAS, P.; KREMER, M. Peer effects, teacher incentives, and the impact of tracking: evidence from a randomized evaluation in Kenya. American Economic Review. 101 (5), 1739-1774, 2011.

FIRPO, S.; JALES, H.; PINTO, C. Measuring peer effects in the Brazilian school system. Applied Economics, Volume 47, Issue 32, 2015.

GAVIRIA, A.; RAPHAEL, S. School-based peer effects and juvenile behavior. The Review of Economics and Statistics, May 2001, 83(2): 257-268, 2001.

HANUSHEK, E. A.; KAIN, J. F.; MARKMAN, J. M.; RIVKIN, S. G. Does peer ability affect student achievement? Journal of Applied Econometrics. 18: 527-544, 2003.

IBGE, 2013. PESQUISA NACIONAL DE SAÚDE DO ESCOLAR, 2012. Instituto Brasileiro de Geografia e Estatística - IBGE. Rio de Janeiro, 2013. Disponível em: http://biblioteca.ibge.gov.br/ visualizacao/livros/liv64436.pdf

KREMER, M.; LEVY, D. Peer Effects and Alcohol Use among College Students. Journal of Economic Perspectives - Volume 22, Number 3 - Summer, Pages 189-206, 2008.

LENAD. II LEVANTAMENTO NACIONAL DE ÁLCOOL E DROGAS - 2012. Ronaldo Laranjeira (Supervisão) [et al.], São Paulo: Instituto Nacional de Ciência e Tecnologia para Políticas Públicas de Álcool e Outras Drogas (INPAD), UNIFESP, 2014.

LUNDBORG, P. Having the wrong friends? Peer effects in adolescent substance use. Journal of Health Economics 25 (2006) 214-233, 2006.

MANSKI, C. F. Identifications Problems in the Social Sciences. Cambridge, MA: Harvard University Press, 1995.

POWELL, L. M.; TAURAS, J. A.; ROSS, H. The importance of peer effects, cigarette prices and tobacco control policies for youth smoking behavior. Journal of Health Economics 24 (2005) 950-968, 2005. 